\title{
NATURAL HISTORY NOTE \\ Recent record of Javan Pipistrelle (Pipistrellus javanicus, Gray 1838) from Chittagong Hill Tracts (CHT), Bangladesh
}

\author{
Anik Saha ${ }^{1, *}$, Mohammed Mostafa Feeroz ${ }^{1}$, Md. Kamrul Hasan ${ }^{1}$
}

\author{
${ }^{1}$ Department of Zoology, \\ Jahangirnagar University, Savar \\ Dhaka 1342, Bangladesh \\ *Corresponding author: an- \\ iksaha0090@gmail.com \\ DOI: https://doi.org/10.14709/ \\ BarbJ.10.1.2017.05 \\ received: April, 9th 2017 \\ accepted: August, 30th 2017
}

\begin{abstract}
Javan Pipistrelle (Pipistrellus javanicus), a native bat species in South Asia, was thought to be present in Bangladesh during the 90s. However, the lack of robust evidence of its occurrence has hampered its inclusion in the Bangladesh IUCN mammal checklist. In a recent survey, a colony of this bat species has been documented in Chittagong Hill Tracts, the southeastern corner of the country. For the species identification, both external and craniodental parameters were considered and compared with other specimen's measurements from nearby countries. This manuscript confirms the distribution of Pipistrellus javanicus in Bangladesh and extends its range over South Asia.
\end{abstract}

Bangladesh is home to 127 species of mammals, of which Chiroptera comprises 35 species within eight families (27\% of all Bangladeshi mammals). Vespertilionidae comprises 14 species, belonging to eight genera including Eptesicus, Hesperoptenus, Kerivoula, Myotis, Pipistrellus, Scotophilus, Scotomanes and Sctozous (IUCN Bangladesh 2015). Four valid species of Pipistrelle bats are reported from Bangladesh viz. P. coromandra, $P$. tenuis, $P$. ceylonicus and $P$. pipistrellus (IUCN Bangladesh 2015) although two other species, $P$. savii and $P$. javanicus are thought to occur here (Khan 2001, Srinivasulu \& Srinivasulu 2005).

The Javan Pipistrelle, Pipistrellus javanicus (Gray, 1838) is a widespread species in Northern and central Southern Asia, Southern China and most of Southeast Asia (Francis et al. 2008). In South Asia, this bat was recorded from Afghanistan, Pakistan, India and Nepal but not in Bhutan or Sri-Lanka (Bates \& Harrison 1997, Srinivasulu \& Srinivasulu 2012). They live in small colonies of five to six members (Molur et al. 2002) and show great tolerance to habitat modification, living in crowded urban areas as well as in primary hill forest where they roost in fallen logs and caves (Francis 2008, Chan et al. 2009).

There have been very few bat studies in Bangladesh and therefore the distribution of certain bat species require further research. During a survey in the southeastern region (Chittagong Hill Tracts), a colony of bats were observed roosting in a mature Teak tree (Tectona grandis) near the periphery of Doluchari Village Common Forest, $20 \mathrm{~km}$ away from Rangamati Town on $14^{\text {th }}$ July 2016 . The colony contained eleven individuals; seven were captured (five females and two males) with mist nets while the rest escaped due to the height of the roost at more than ten meters. Standard protocol was used in mist netting and handling bats (Kunz \& Kurta 1988) and the measurements (morphological and cranio-dental attributes) were taken with digital slide caliper with an accuracy of $0.01 \mathrm{~mm}$. Among the seven individuals, two were euthanised with chloroform; one was preserved as a voucher specimen (WLMA-0018) in the Wildlife museum at the Department of Zoology, Jahangirnagar University and another was used for skull extraction. The rest of the captured individuals were released after taking the necessary measurements.

Based on the external and cranio-dental measurements, the specimens were identified as Pipistrellus javanicus. Notable measurements include: forearm length (FA: $34.54 \pm 0.52 \mathrm{~mm}$ ), greatest length of skull (GTL: $13.84 \mathrm{~mm}$ ), condylocanine length (CCL: $12.94 \mathrm{~mm}$ ), maxillary toothrow $\left(\mathrm{C}-\mathrm{M}^{3}: 5.16 \mathrm{~mm}\right)$, mandibular tooth row $\left(\mathrm{C}-\mathrm{M}_{3}: 5.35 \mathrm{~mm}\right)$, posterior palatal width $\left(\mathrm{M}^{3}-\mathrm{M}^{3}: 6.07 \mathrm{~mm}\right)$ and mandibular length (ML: $10.38 \mathrm{~mm}$ ) (Table 1 ). Body coloration varied between sexes, the male was medium brown, while the female was chestnut brown; the interfemoral membrane were without hairs; the bats had relatively straight traguses (Fig. 1); upper canine bicuspid and upper posterior premolar $\left(\mathrm{pm}^{4}\right)$ contained distinct shelf forming with antero-lingual projection and wide anterior cingulum (Fig. 2).

At present, eight Pipistrelle bat species are reported from Southern Asia; three of which are in the javanicus subgroup such as $P$. javanicus, $P$. paterculus and $P$. abramus (Corbet \& Hill 1992, Srinivasulu et al. 2011). Compared to P. javanicus (FA: 34.54 (34.10-35.31) mm; GTL: 13.84 mm), the two other species are smaller in size: $P$. paterculus (FA: 30.9 (29.2-34) mm; GTL: $12.1(11.7-12.6) \mathrm{mm}$ ) and $P$. abramus (FA: 30.41 (28.17-30.85) mm; GTL: 11.2 (11.712.6) $\mathrm{mm}$ (Bates and Harrison 1997, Srinivasulu et al. 2010, Srinivasulu et al. 2011) (Table 2). In addition, P. javanicus has distinct secondary cusp in upper canine which is absent in $P$. paterculus (Srinivasulu et al. 2010). In the ceylonicus 


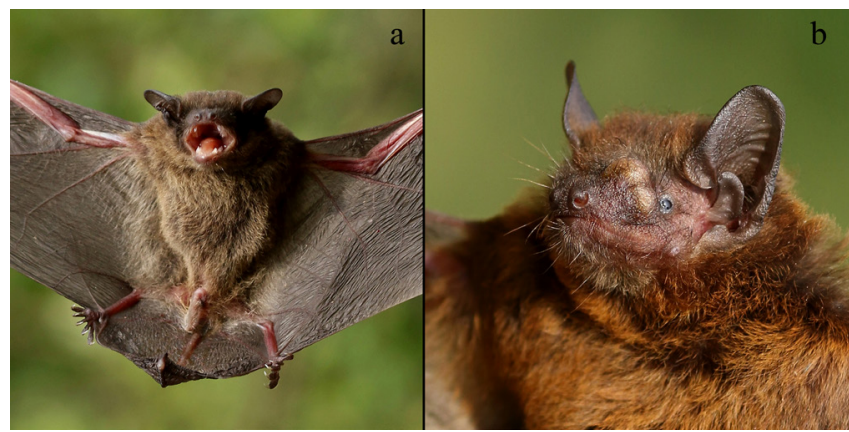

Fig. 1 - Pipistrellus javanicus from Bangladesh, (a) male with medium brown coloration and (b) female have chestnut brown pelage.

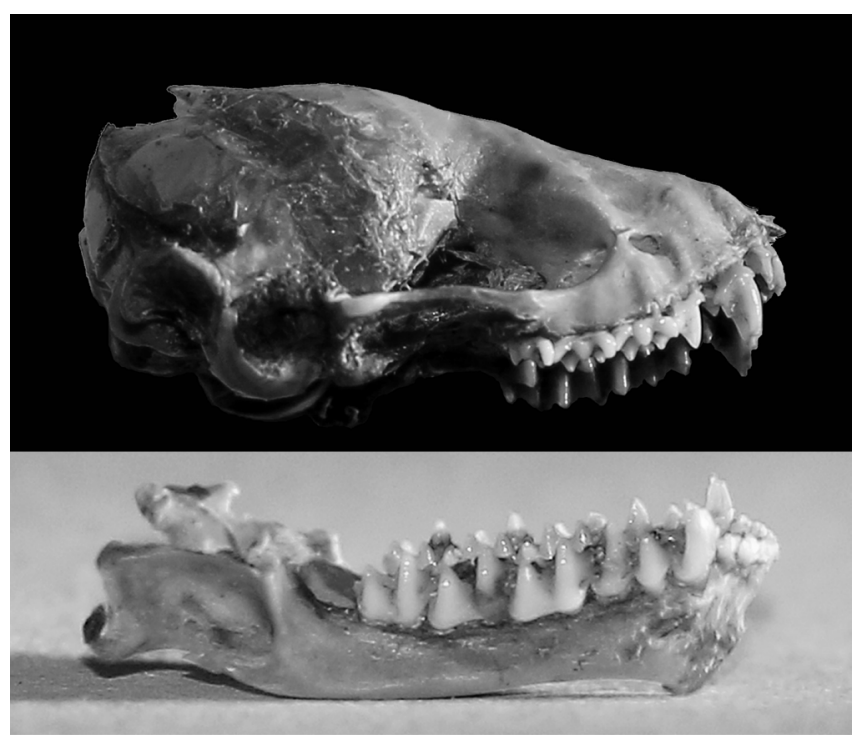

Fig. 2 - The robust skull of Pipistrellus javanicus, upper canine has distinct secondary cusp. subgroup, P. ceylonicus (FA: 37.2 (33.0-42) mm; GTL: 15 (14.4-15.8) mm; CCL: 13.7 (13.1-14.3) mm; ML: 11.2(10.612.0) $\mathrm{mm}$ ) is comparatively larger than $P$. javanicus (FA: 34.54 (34.10-35.31) mm; GTL: $13.84 \mathrm{~mm}$; CCL: $12.94 \mathrm{~mm}$; ML: $10.38 \mathrm{~mm}$ ) (Table 2). P. ceylonicus has sparse hair on the interfemoral membrane, which is absent in our specimens, helping to confirms it as $P$. javanicus (Srinivasulu et al. 2010). The rest of the bats from the pipistrelle subgroup ( $P$. pipistrellus) and coromandra subgroup ( $P$. coromandra and $P$. tenuis) are notably smaller than $P$. javanicus (Table 2$)$. $P$. kuhlii can be separated by larger tail length, TL: 41.1 (3345) compare to our specimens, TL: 32.53 (31.05-34.02) mm (Table 2). Additionally, P. kuhlii has a white border on the edges of the interfemoral membrane, which is absent in our P. javanicus specimens (Fig. 1a).

Kock (1996) reported the presence of $P$. javanicus from Bangladesh but no voucher specimen was collected. Bates \& Harrison (1997), Molur et al. (2002) and Khan (2008) recorded further occurrences without new morphological data, only reporting the species based on Kock (1996). As a result, IUCN Bangladesh (2015) excluded P. javanicus from the "mammals checklist" as there was not enough data to support its presence in the country. Thus, this new distribution record proves that this bat exists in the mixedevergreen forest at Chittagong Hill Tracts (CHT), Bangladesh.

No threats were observed to this colony of $P$. javanicus as local people did not know about their presence in the area. However, the roosting tree was found at the periphery of the Village Common Forest (VCF) where cutting trees or hunting animals were prohibited. It is possible that further colonies of $P$. javanicus may be found over the study area.

\section{ACNOWLEDGEMENTS}

The authors are grateful to the authorities of Wildlife Rescue Centre (WRC), Jahangirnagar University and

Table 1 - Morphological and cranio-dental measurements (in $\mathrm{mm}$ ) of $P$. javanicus from Bangladesh. Abbreviations are as follows: HB: head body, FA: forearm, 3mt: third metacarpal, $1 \mathrm{ph} 3 \mathrm{mt}$ : first phalanx of third metacarpal, $2 \mathrm{ph} 3 \mathrm{mt}$ : second phalanx of third metacarpal, TIB: tibia length, HF: hind feet, TL: tail length, EL: ear length, Tr.: tragus length, GTL: greatest length of the skull, CCL: condylo-canine length, $\mathrm{BB}$ : braincase, ZB: zygomatic breadth, $\mathrm{C}^{1}-\mathrm{C}^{1}$ : anterior palatal width, $\mathrm{M}^{3}-\mathrm{M}^{3}$ : posterior palatal width, $\mathrm{C}-\mathrm{M}^{3}$ : maxillary tooth row, $\mathrm{C}-\mathrm{M}_{3}$ : mandibular tooth row and ML: mandible length.

\begin{tabular}{lccc|lc}
\hline \multicolumn{2}{l}{ Morphological Attributes in $\mathbf{~ m}$} & & \multicolumn{2}{l}{ Cranial Attributes in $\mathbf{~ m m}$} \\
\hline Parameters & Mean & SD & Range & Parameter & Length \\
\hline $\mathrm{HB}$ & 49.92 & 1.79 & $47.28-51.32$ & $\mathrm{GTL}$ & 13.84 \\
\hline $\mathrm{FA}$ & 34.54 & 0.52 & $34.10-35.31$ & $\mathrm{CCL}$ & 12.94 \\
\hline $3 \mathrm{mt}$ & 32.15 & 0.51 & $31.46-32.54$ & $\mathrm{BB}$ & 6.95 \\
\hline $1 \mathrm{ph} 3 \mathrm{mt}$ & 12.33 & 0.76 & $11.47-13.31$ & $\mathrm{ZB}$ & 8.68 \\
\hline $2 \mathrm{ph} 3 \mathrm{mt}$ & 17.13 & 0.67 & $16.18-17.77$ & $\mathrm{C}^{1}-\mathrm{C}^{1}$ & 4.46 \\
\hline TIB & 12.22 & 0.37 & $11.97-12.78$ & $\mathrm{M}^{3}-\mathrm{M}^{3}$ & 6.07 \\
\hline $\mathrm{HF}$ & 7.48 & 0.11 & $7.33-7.58$ & $\mathrm{C}-\mathrm{M}^{3}$ & 5.16 \\
\hline TL & 32.53 & 1.22 & $31.05-34.02$ & $\mathrm{C}-\mathrm{M}_{3}$ & 5.35 \\
\hline EL & 11.88 & 0.86 & $11.38-13.17$ & ML & 10.38 \\
\hline Tr. & 5.33 & 0.20 & $5.03-5.46$ & & \\
\hline
\end{tabular}


Table 2 - Comparative measurements (in $\mathrm{mm}$ ) of different Pipistrelle bats from South Asia according to Srinivasulu et al. 2010 and Srinivasulu et al. 2011. Abbrevations are as follows: FA: forearm, TL: tail length, GTL: greatest length of the skull, CCL: condylo-canine length, $\mathrm{C}-\mathrm{M}^{3}$ : maxillary tooth row, $\mathrm{C}-\mathrm{M}_{3}$ : mandibular tooth row and $\mathrm{ML}$ : mandible length.

\begin{tabular}{lccccccc}
\hline Attributes $(\mathbf{m m})$ & FA & TL & GTL & CCL & C-M & C-M & ML \\
\hline Specimens & $34.10-35.31$ & $31.05-34.02$ & 13.84 & 12.94 & 5.16 & 5.35 & 10.38 \\
\hline P. javanicus & $30.0-36.0$ & $26.0-40.0$ & $13-14.6$ & $11.9-13.1$ & $4.6-5.2$ & $4.8-5.5$ & $9.3-10.7$ \\
\hline P. paterculus & $29.2-34.0$ & $31.0-38.0$ & $11.7-12.6$ & $10.6-11.6$ & $4.1-4.8$ & $4.4-5.0$ & $8.4-9.1$ \\
\hline P. abramus & $28.17-30.85$ & $29.66-32.2$ & $10.98-11.43$ & $10.19-10.57$ & $3.68-3.89$ & $4.04-4.13$ & $7.46-8.07$ \\
\hline P. ceylonicus & $33.0-42.0$ & $30.0-45.0$ & $14.4-15.8$ & $13.1-14.3$ & $5.2-5.9$ & $5.7-6.5$ & $10.6-12.0$ \\
\hline P. pipistrellus & $30.0-30.6$ & $29.0-35.0$ & $11.9-12.5$ & $10.4-11.3$ & $4.1-4.4$ & $4.3-4.7$ & $7.9-8.7$ \\
\hline P. coromandra & $25.5-34.3$ & $22.0-39.0$ & $11.8-13.1$ & $10.6-11.9$ & $3.9-4.6$ & $4.1-5.1$ & $8.2-9.5$ \\
\hline P. tenuis & $25.0-30.2$ & $20.0-35.0$ & $10.7-12.1$ & $9.3-10.7$ & $3.5-4.1$ & $3.8-4.4$ & $7.2-8.3$ \\
\hline P. kuhlii & $33.4-36.0$ & $33.0-45.0$ & $12.9-13.9$ & $12.0-12.9$ & $4.6-5.0$ & $5.0-5.5$ & $9.3-10.4$ \\
\hline
\end{tabular}

Arannayk Foundation Bangladesh for all kind of logistic supports to carry out the research work. Special thanks to the authorities of Doluchari Village Common Forest for approving permission to work on and the local people for their assistance during the fieldwork.

\section{REFERENCES}

BATES, P.J.J. \& HARRISON, D.L. (1997). Bats of the Indian Subcontinent. Sevenoaks: Harrison Zoological Museum Publications, Kent, United Kingdom, 258 pp.

CHAN, K.W., LIM, K.K. \& LEONG, T.M. (2009). The Javan Pipistrelle, Pipistrellus javanicus (Mammalia: Chiroptera: Vespertilionidae) in Singapore. Nature in Singapore, 2: 323-327.

CORBET, G.B. \& HILL, J.E. (1992). The Mammals of the Indomalayan Region: a systematic review. Natural History Museum Publications, Oxford University Press, Oxford, United Kingdom, 488 pp.

FRNACIS, C.M. (2008). A Field Guide to the Mammals of South-East Asia. New Holland Publishers Ltd., London, United Kingdom, 392 pp.

FRANCIS, C., ROSELL-AMBAL, G., TABARNAZA, B., HEANEY, L., MOLUR, S. \& SRINVASULU, C. (2008). Pipistrellus javanicus. The IUCN Red List of Threatened Species 2008: e.T17344A7006409. https://doi.org/10.2305/ IUCN.UK.2008.RLTS.T17344A7006409.en

IUCN BANGLADESH. (2015). Red List of Bangladesh Volume 2: Mammals. IUCN, International Union for Conservation of Nature, Bangladesh Country Office, Dhaka, Bangladesh, $232 \mathrm{pp}$.

KHAN, M.A.R. (2001). Status and distribution of bats in Bangladesh with notes on their ecology. Zoos' Print Journal, 16(5): 479-483. https://doi.org/10.11609/JoTT. ZPJ.16.5.479-83
KHAN, M.M.H. (2008). Protected Areas of Bangladesh - A Guide to Wildlife. Nishorgo Program. Bangladesh Forest Department, Dhaka, Bangladesh, 304 pp.

KHAN, M.M.H. (2015). Chittagong Hill Tracts-The Land of Diversity. Bangladesh Forest Department, Dhaka, Bangladesh, $167 \mathrm{pp}$.

KOCK, D. (1996). Fledermause aus Nepal (Mammalia: Chiroptera). Senckenbergiana Biologica, 75(1/2): 15-21.

KUNZ, T.H. \& KURTA, A. (1988). Capture methods and holding devices. pp. 1-29. In T.H. Kunz (ed). Ecological and behavioral methods for the study of bats. Smithsonian Institution Press, Washington, D.C., USA, 533 pp.

MOLUR, S., MARIMUTHU, G., SRINIVASULU, C., MISTRY, S., HUTSON, A.M. BATES, P.J.J., WALKER, S., PRIYA, K.P. \& PRIYA, A.R.B. (ed). (2002). Status of South Asian Chiroptera: Conservation Assessment and Management Plan (C.A.M.P.) Workshop Report. Coimbatore: Zoo Outreach Organisation, Conservation Breeding Specialist Group South Asia, and Wildlife Information \& Liaison Development Society, Coimbatore, India, 154 pp.

SRINIVASULU, B. \& SRINIVASULU, C. (2005). A review of chiropteran diversity of Bangladesh. BAT NET-CCINSA Newsletter, 6(2): 6-11.

SRINIVASULU, C., RACEY, P.A. \& MISTRY, S. (2010). A key to the bats (Mammalia: Chiroptera) of South Asia. Journal of Threatened Taxa, 2(7): 1001-1076.

SRINIVASULU, B., SRINIVASULU, C., KAUR, H. \& SRINIVASULU, A. (2011). A new distribution record of the Japanese Pipistrelle (Pipistrellus abramus (Temminck, 1840); Mammalia, Chiroptera) in India. Acta Zoologica Lituanica, 21(4): 268-272. https://doi.org/10.2478/ v10043-011-0029-8

SRINIVASULU, C. \& SRINIVASULU, B. (2012). South Asian Mammals: Their Diversity, Distribution, and Status. Springer International Publishing, New York, USA, 98 pp. https://doi.org/10.1007/978-1-4614-3449-8_2 